\title{
Development of a DP980 steel with low cooling rate requirement
}

\author{
Libo Pan ${ }^{1, *}$, Wen Tan ${ }^{2}$, Wenqiang Zhou ${ }^{2}$ and Junlin Wang ${ }^{2}$ \\ ${ }^{1}$ Insititute of Intelligent Manufacturing, Jianghan University, 430056, Wuhan, China \\ ${ }^{2}$ Baosteel Central Research Institute, 430056, Wuhan, China
}

\begin{abstract}
DP980 is a promising light-weightening material in car body. To avoid high investment of strong cooling system, a new DP980 steel with low cooling rate requirement was developed. The mechanical properties and microstructure were analyzed under different manufacturing process. It could be concluded that the chemical composition design should be reasonable and of low cost to achieve both high strength and also austenite to martensite transformation at low cooling rate. Strength increased with coiling temperature decreasing during hot rolling, and higher annealing temperature and lower over aging temperature were favourable to higher strength. The austenite-martensite transforming could be completed at even lower rapid cooling rate of $20^{\circ} \mathrm{C} / \mathrm{s}$. Through optimized manufacturing process parameters, the new DP steel product with good mechanical properties could be obtained successfully, which provided a new option for normal production line to produce ultra high strength steel.
\end{abstract}

\section{Introduction}

According to the requirement of light weight and safety in automotive industry, advanced high strength steel had been increasingly used for car body design due to the properties of high strength and good formability[1-2]. Currently Dual phase steels (DP) with tensile strength of $590 \mathrm{MPa}$ and $780 \mathrm{Ma}$ are the main steel grades applied in body in white, as the continuous escalation of lightweighting, DP980 is considered to be more and more popular for its higher strength level and acceptable ductility. However, the stability of its mechanical properties is very difficult to be controlled because of the high strength and high sensitivity to manufacturing process[3-5]. Many scholars made a lot of researches on this steel product[6-8]. Generally dual phase steel is composed of ferrite and martensite, and the higher the strength is, the more amount of martensite it has. Austenite to martensite transformation is related to cooling rate, therefore, to obtain high volume fraction of martensite, the cooling system of the production line need to strong to some extent. In steel industry, special lines equipped with strong cooling system were built to manufacture DP980 and some even higher strength level grades. Considering the huge investment of new special lines, it's a big challenge to manufacture DP980 in the normal production line with cooling rate no higher than $30^{\circ} \mathrm{C} / \mathrm{s}$. In this study, a new DP980 with special chemical composition and process design suitable for normal production line was developed, and it showed good mechanical properties.

\section{Chemical composition}

To enable austenite to martensite transforming at low cooling rate, chemical composition design is one of the key points. More alloys should be added comparing to the product manufactured in special lines, and compromise should be made in terms of various kinds of alloys addition for the consideration of low cost. In dual phase steel, C amount inside the martensite directly decides the strength of martensite and the strength of the material, but high amount of $\mathrm{C}$ would worsen the formability and be bad for welding property. $\mathrm{Si}, \mathrm{Mn}$ and $\mathrm{Cr}$ are the normal elements added in dual phase steel to ensure high strength. Refined ferrite grain size could be obtained by $\mathrm{Nb}$ addition to enhance the hardness of ferrite which contributes to good flangeability. B is helpful to improve the hardenability. Therefore, chemical composition design should be reasonable and of low cost to achieve both austenite to martensite transformation at low cooling rate and also high strength, good formability as well. The main chemical composition of this DP980 was shown in Table 1.

Table 1. The Chemical Composition.

\begin{tabular}{|c|c|c|c|c|c|c|c|}
\hline \multicolumn{7}{|c|}{ Chemical Composition [wt\%] } \\
\hline $\mathrm{C}$ & $\mathrm{Si}$ & $\mathrm{Mn}$ & $\mathrm{P}$ & $\mathrm{Cr}$ & $\mathrm{Nb}$ & $\mathrm{Ti}$ & $\mathrm{B}$ \\
\hline$\leq 0.2$ & $\leq 0.2$ & $\leq 2.5$ & $\leq$ & $\leq 0.7$ & $\leq 0.1$ & $\leq 0.1$ & $\leq 0.002$ \\
& & & 0.02 & & & & \\
\hline
\end{tabular}

\section{Manufacturing process}

The key point for DP steel melting is controlling segregation, desulphurization and degassing. The combination of LF and RH process flow was recommended during steel making.

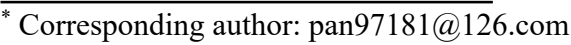




\subsection{Hot rolling}

In hot rolling process, heating temperature, final rolling temperature and coiling temperature (CT) were the key technology parameters. Final rolling temperature has effect on the grain size of ferrite, and higher coiling temperature could lower the strength of hot rolled sheet which will help to be rolled easily, but might lead to insufficient strength for the final product. In trials three different coiling temperatures $690^{\circ} \mathrm{C}, 670^{\circ} \mathrm{C}$ and $650^{\circ} \mathrm{C}$ were conducted and the sheet thickness after hot rolling was $3.2 \mathrm{~mm}$. The hot rolled samples had been taken to evaluate the strength and rolling feasibility. The mechanical properties of hot rolled samples under different coiling temperature were shown in Table 2.

From the result, it can be seen the strengths including yield strength (YS) and ultimate tensile strength (UTS) increased with coiling temperature decreasing. The coil with coiling temperature of $690^{\circ} \mathrm{C}$ was chosen to be cold rolled with a thickness reduction rate of $50 \%$ to avoid massive rolling force or potential damage to the rolling line. The typical microstructure mainly composed of Ferrite and Pearlite after hot rolling with coiling temperature at $690^{\circ} \mathrm{C}$ was shown in Fig. 1, in which there was apparent banded structure after hot rolling.

Table 2. Mechanical properties at different coiling temperature.

\begin{tabular}{|c|c|c|c|c|}
\hline \multirow{2}{*}{ Samples } & \multirow{2}{*}{$\mathrm{CT}$} & \multicolumn{3}{|c|}{ Mechanical Properties } \\
\cline { 3 - 5 } & & $\begin{array}{c}\text { YS } \\
(\mathrm{MPa})\end{array}$ & $\begin{array}{c}\text { UTS } \\
(\mathrm{MPa})\end{array}$ & $\begin{array}{c}\text { Elongation } \\
\text { A80mm(\%) }\end{array}$ \\
\hline No.1 & $690^{\circ} \mathrm{C}$ & 517 & 663 & 18.9 \\
\hline No.2 & $670^{\circ} \mathrm{C}$ & 553 & 699 & 17.6 \\
\hline No.3 & $650^{\circ} \mathrm{C}$ & 598 & 736 & 15.4 \\
\hline
\end{tabular}

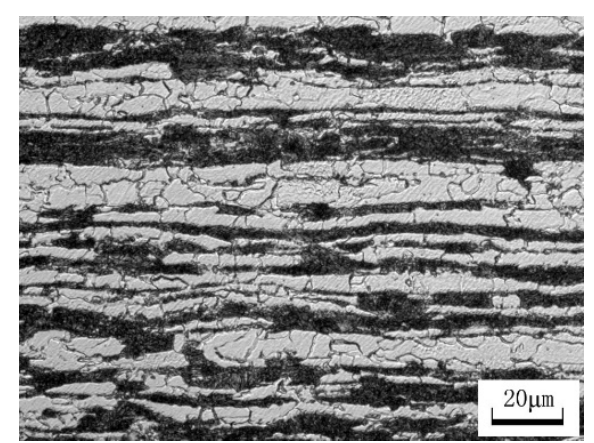

Fig. 1. Microstructure after hot rolling with CT at $690^{\circ} \mathrm{C}$.

\subsection{Annealing experiments}

Continuous annealing process is critical to the final properties during dual phase steel manufacturing[9]. The dual-phase microstructure is obtained when it is annealed within its intercritical annealing temperature range and suitably quenched. The intercritical annealing temperature controls the extent of partitioning of alloying elements between ferrite and austenite and determines the volume fraction and characteristics of ferrite and martensite present in the steel. The cooling rate should be high enough to make austenite to martensite transformation. Over aging stage is also critical to the strength of dual phase steel, in which, the steel can get tempered. Generally, as the over aging temperature increases, the tensile strength will decrease because of the decomposition of martensite.

\subsubsection{Experiment scheme}

The steel samples selected to study were provided as $1.6 \mathrm{~mm}$ thick cold roll strips with $50 \%$ cold rolling reduction. Continuous annealing experiments were performed in a laboratory Iwatani Surtec hot-dip simulator employing several distinct heat treatment cycles, shown in Fig.2. The experiments were made on deferent samples at deferent intercritical annealing temperatures $T_{l}$, different rapid cooling rates $v$ and different over aging temperatures $T_{3}$.

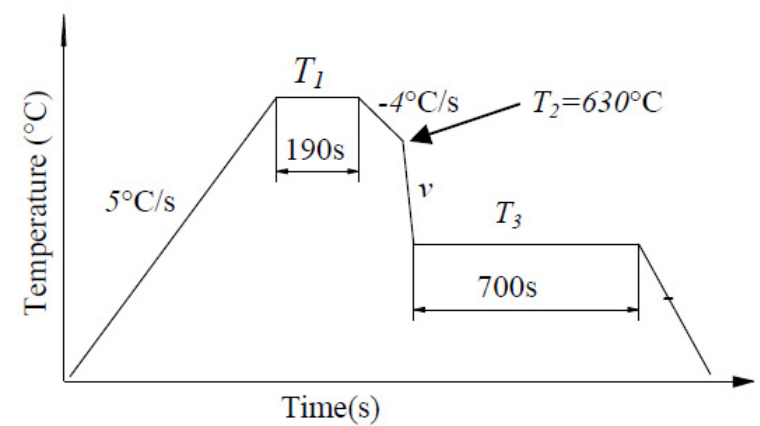

Fig. 2. Schematic illustration of continuous annealing process.

As shown in Table 3, the experiment schemes with different combinations of technology parameters were employed.

Table 3. Experiments with different annealing parameters.

\begin{tabular}{|c|c|c|c|}
\hline No. & $\begin{array}{c}\text { Intercritical } \\
\text { annealing } \\
\text { temperature } T_{l}\left({ }^{\circ} \mathrm{C}\right)\end{array}$ & $\begin{array}{c}\text { Rapid } \\
\text { cooling rate } \\
v\left({ }^{\circ} \mathrm{C} / \mathrm{s}\right)\end{array}$ & $\begin{array}{c}\text { Over aging } \\
\text { temperature } \\
T_{3}\left({ }^{\circ} \mathrm{C}\right)\end{array}$ \\
\hline 1 & 790 & 30 & 300 \\
\hline 2 & 810 & 30 & 300 \\
\hline 3 & 830 & 30 & 300 \\
\hline 4 & 810 & 20 & 300 \\
\hline 5 & 810 & 50 & 300 \\
\hline 6 & 810 & 30 & 270 \\
\hline 7 & 810 & 30 & 250 \\
\hline
\end{tabular}

After annealing, the samples were grinded, polished and eroded to be analyzed microstructure by optical microscopy. Ethanol with 5\% content of nitric acid was used as corrodent at corroding temperature of $20-25^{\circ} \mathrm{C}$. Tensile tests were carried out by using a ZWICK test machine.

\subsubsection{Result and analysis}

Experiment schemes 1 to 3 were carried out to mainly evaluate the effect of different aneealing temperature on the material. The following gave the metallographic results at different annealing dwelling temperature as shown in Fig.3. There were more martensite in samples annealed at $810^{\circ} \mathrm{C}$ than that at $790^{\circ} \mathrm{C}$. There was obvious 
banded structure when the annealing temperature was $830^{\circ} \mathrm{C}$. From the result, it could be known that the volume fraction of martensite increased with annealing temperature going up.

The mechanical properties results were shown in Fig.4, which indicated that ultimate tensile strength slightly increased with annealing temperature increasing, and the values were $1020 \mathrm{MPa}, 1040 \mathrm{MPa}$ and $1060 \mathrm{MPa}$, respectively. Generally for DP steel, higher volume fraction of martensite results in higher ultimate tensile strength[10]. There was no obvious law in regard to yield strength changing. The lowest yield strength was $473 \mathrm{MPa}$ when annealing temperature was $810^{\circ} \mathrm{C}$. The higher the annealing temperature was, the higher the elongation was. The elongation reached $11.4 \%$ at annealing temperature of $830^{\circ} \mathrm{C}$. However, higher annealing temperature meant higher energy consumption, and there would be some comprise between mechanical properties and annealing temperature in practical manufacturing.
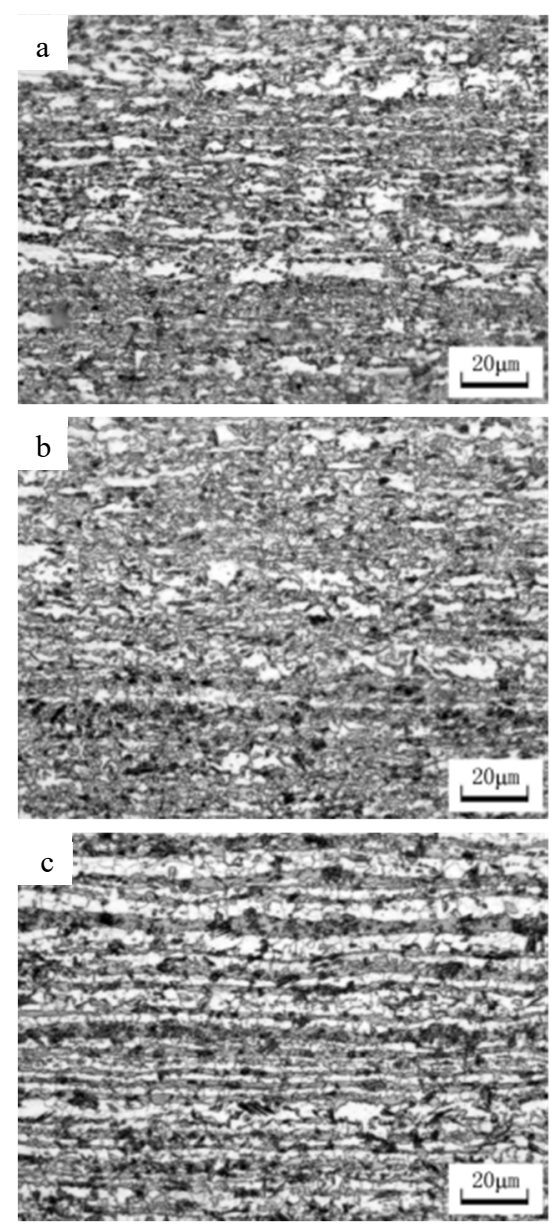

Fig. 3. Microstructure at different annealing temperature. (a) $\mathrm{T}_{1}=790^{\circ} \mathrm{C}$, (b) $\mathrm{T}_{1}=810^{\circ} \mathrm{C}$, (c) $\mathrm{T}_{1}=830^{\circ} \mathrm{C}$.

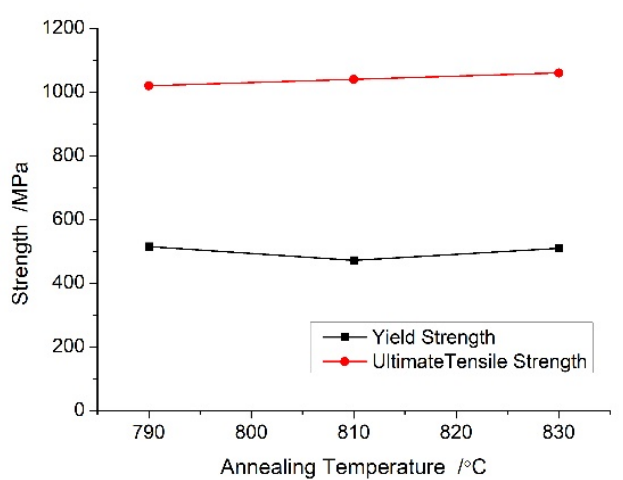

(a)

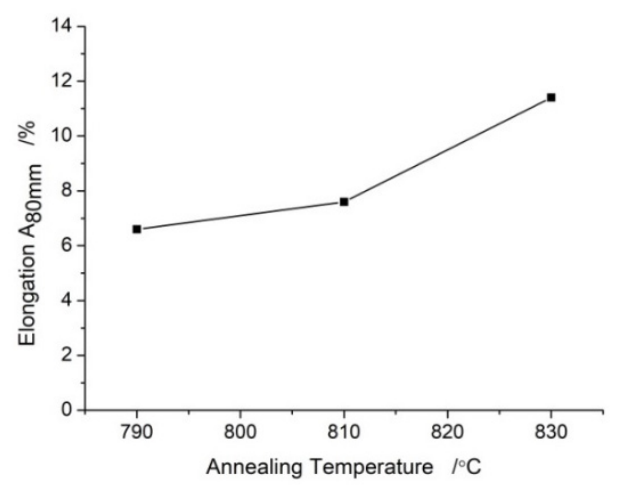

(b)

Fig. 4. Mechanical properties at different annealing temperature. (a) Strength, (b) Elongation.

Experiment schemes 2, 4 and 5 were carried out to mainly evaluate the effect of different rapid colling rate on the material. The metallographic results showed that there were ferrite and martensite dual phases at all different rapid cooling rates, and the austenite-martensite transforming could be completed at even lower rapid cooling rate of $20^{\circ} \mathrm{C} / \mathrm{s}$, which meant the chemical composition design for this type of DP980 steel was rational. The microstructure of the sample at rapid cooling rate of $20^{\circ} \mathrm{C} / \mathrm{s}$ was shown in Fig.5. The mechanical properties for different rapid cooling rate were shown in Fig.6. From the strength curves, it could be seen that both yield strength and ultimate tensile strength didn't change too much with rapid cooling rate changing. This type of DP980 steel was not sensitive to rapid cooling rate. The highest elongation was obtained at rapid cooling rate of $20^{\circ} \mathrm{C} / \mathrm{s}$.

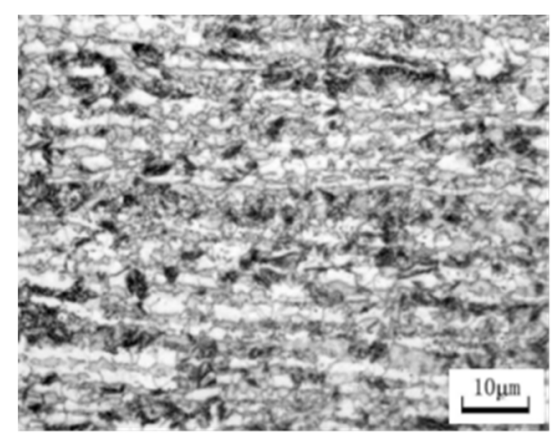

Fig. 5. Microstructure at cooling rate of $20^{\circ} \mathrm{C} / \mathrm{s}$. 


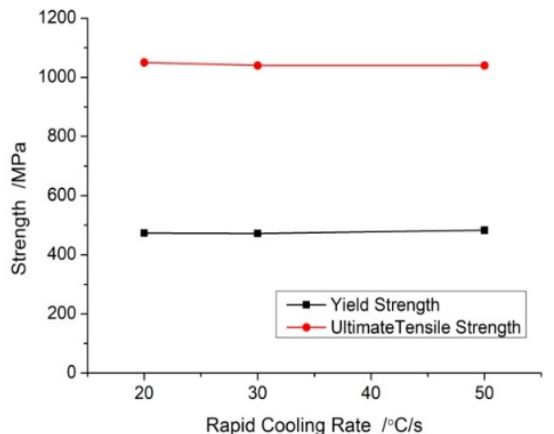

(a

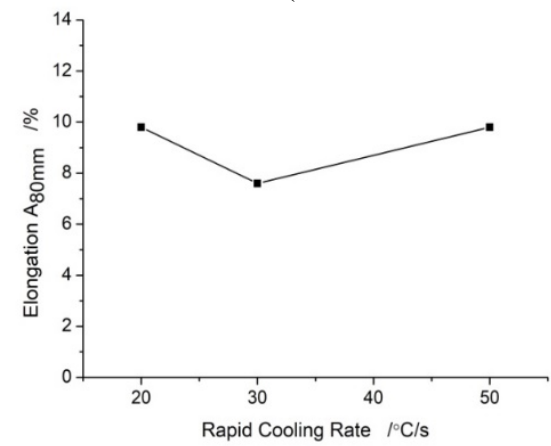

(b

Fig. 6. Mechanical properties at different rapid cooling rate. (a) Strength, (b) Elongation.

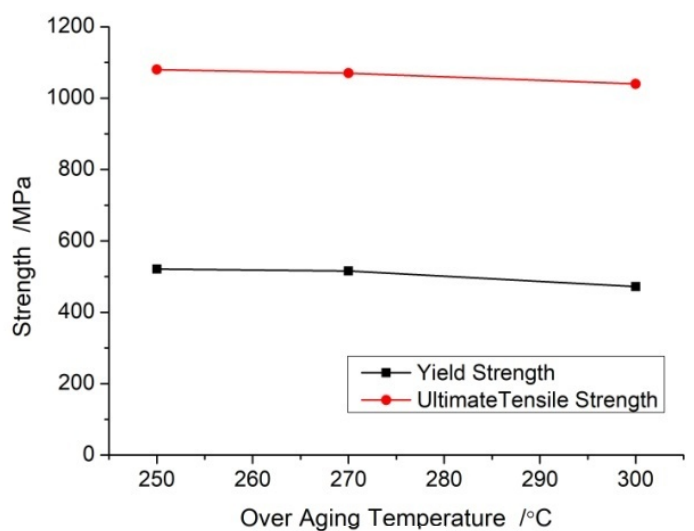

(a)

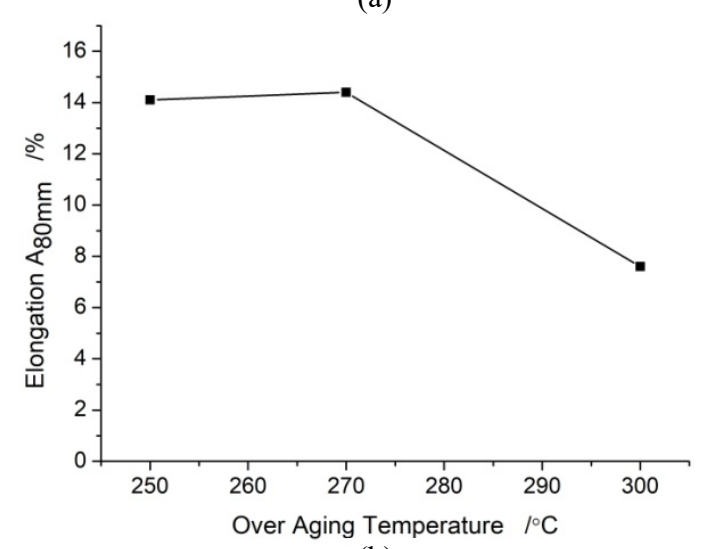

(b)

Fig. 7. Mechanical properties at different over aging temperature. (a) Strength, (b) Elongation.

As stated above, over aging temperature is critical to the strength of DP steel, especially ultimate tensile strength, because a lot of martensite islands will be partially resolved and some carbide will precipitate among martensite islands if high over-aging temperature is employed during annealing. Higher over aging temperature could accelerate the decomposition of martensite[11]. Experiment schemes 2, 6 and 7 were carried out to mainly evaluate the effect of different over aging temperature on the material. From the mechanical properties result as shown in Fig.7, it could be known that both yield strength and ultimate tensile strength decreased with over aging temperature increasing. As over aging temperature changed from $250^{\circ} \mathrm{C}$ to $300^{\circ} \mathrm{C}$, the yield strength decreased by nearly $50 \mathrm{MPa}$, and the ultimate tensile strength decreased by $40 \mathrm{MPa}$. The highest elongation was obtained at over aging temperature of $270^{\circ} \mathrm{C}$.

\subsection{Final product from production line}

Based on the study on continuous annealing experiment, the optimized annealing process could be determined as shown in Table 4 by considering both manufacturing cost and mechanical properties.

Table 4. Optimized continuous annealing process.

\begin{tabular}{|c|c|c|}
\hline $\begin{array}{c}\text { Intercritical annealing } \\
\text { temperature } T_{I}\left({ }^{\circ} \mathrm{C}\right)\end{array}$ & $\begin{array}{c}\text { Rapid } \\
\text { cooling rate } v \\
\left({ }^{\circ} \mathrm{C} / \mathrm{s}\right)\end{array}$ & $\begin{array}{c}\text { Over aging } \\
\text { temperature } T_{3} \\
\left({ }^{\circ} \mathrm{C}\right)\end{array}$ \\
\hline 810 & $20-30$ & 270 \\
\hline
\end{tabular}

The new type of DP980 steel was manufactured in production line according to above annealing process parameters. The mechanical properties of the final product were obtained as shown in Table 5. The mechanical properties could meet the standard requirement of DP980. And the final product was sent to customer for welding and part stamping trials, and this sucessfully developed material showed good performance in welding and forming.

Table 5. Mechanical properties of final product.

\begin{tabular}{|c|c|c|c|}
\hline$\cdot$ Type & $\begin{array}{c}\text { YS } \\
(\mathrm{MPa})\end{array}$ & $\begin{array}{c}\text { UTS } \\
(\mathrm{MPa})\end{array}$ & $\begin{array}{c}\text { Elongation } \\
\text { A80mm(\%) }\end{array}$ \\
\hline DP980 & 572 & 1090 & 12.5 \\
\hline $\begin{array}{c}\text { Standard } \\
\text { requirement }\end{array}$ & $550-730$ & $\geq 980$ & $\geq 7$ \\
\hline
\end{tabular}

\section{Conclusion}

With the development of light-weightening, DP980 is considered to be more and more popular for its higher strength level and accepted formability. A DP980 steel with low cooling rate requirement had been developed in normal production line to avoid special investment of strong cooling system. The following could be concluded.

(1) The chemical composition design is critical. More alloys need to be added to achieve high strength and ensure austenite-martensite transforming at low cooling rate.

(2) During hot rolling, strength increased with coiling temperature decreasing. To avoid massive roling force or potential damage to the rolling line, the coil with coiling 
temperature of $690^{\circ} \mathrm{C}$ was chosen to be cold rolled with a thickness reduction rate of $50 \%$.

(3) Different combinations of annealing process parameters were studied. The ultimate tensile strength and elongation increased with annealing temperature increasing. This new DP980 steel was not sensitive to rapid cooling rate, and the austenite-martensite transforming could be completed at even lower rapid cooling rate of $20^{\circ} \mathrm{C} / \mathrm{s}$. Both yield strength and ultimate tensile strength decreased with over aging temperature increasing.

(4) This DP steel product with good mechanical properties could be obtained by using optimized manufacturing process parameters.

\section{References}

1. Z. K. Teng, X. M. Chen. Mater. Sci. Eng., A 618, 645(2014)

2. W. R. Wang, C. W. He, Z. H. Zhao, X. C. Wang, Mater. Des. 32, 3320(2011)

3. D. Y. Dong, Y. Liu, L. Wang, C. S. Liu. Adv. Mater. Res. 509, 40(2012)

4. P. Tsipouridis, E. Werner, C. Krempaszky, E. Tragl, Steel. Res. Int. 77, 654(2006)

5. K. Hasegawa, K. Kawamura, T. Urabe, Y. Hosoya, ISIJ Int. 44, 603(2004)

6. F. Zhang, A. Ruimi, P. C. Wo, D.P. Field, Mater. Sci. Eng., A 659, 93(2016)

7. Q. J. Zhou, F. Huang, L. Wang, Baosteel Tech. Res. 10, 40(2016)

8. W. S. Xia, X. Ma, C. H. Wei, W. Y. Tian, J. Huazhong Uni. Sci. Technol (Natural Science Edition). 45, 70(2017)

9. Z. Kong, J. Zhang, H. B. Li, N. Kong, Steel. Res. Int. 89, 1(2018)

10. A. K. Jena, M. C. Chaturvedi, Mater. Sci. Eng., A 100, 1(1998)

11. L. B. Pan, J. Xiong, Z. J. Zuo, W. Tan, J. L. Wang, W. X. Yu, Procedia Manufacturing, 50, 761(2020) 